\title{
Pharmaceutical Pellets: A Versatile Carrier for Oral Controlled Delivery of Drugs
}

\author{
Niti Yadav* and Anurag Verma \\ School of Pharmaceutical Sciences, IFTM University, Moradabad, 244001, INDIA.
}

\begin{abstract}
In pharmaceutical industries, pellets are multiparticulate dosage form which was formed by the agglomeration of fine powdered excipient and drugs together that leads to the formation of small free flowing spherical or semi spherical particles. This technique is called as pelletization process. Pellets are typically varied between 500-1500 $\mu \mathrm{m}$ in size for pharmaceutical applications. It is of great interest over other similar techniques due to its uniformity of dose, less susceptibility of dose dumping, less friability etc. With the advent of controlled release technology, drug loaded pellets have been widely investigated for its control release property in gastrointestinal tract. This review will provide an insight into previous studies on pelletization techniques, investigation of various pelletization techniques namely: layering, extrusion spheronization, cryopelletization, hot melt extrusion. It also gives a brief idea about the evaluation of pellets; parameters affecting pelletization, the different available marketed pellet formulation.
\end{abstract}

Key words: Cryopelletization, Extrusion, Fluidized bed Processor, Layering, Spheronization.

\section{INTRODUCTION}

During recent years, considerable energy and expense have been paid to devise methods for producing dosage forms having unique morphologies in order to fulfill various requirements for utilizing a variety of medicinal substances. Drug-loaded spherical multiparticulates, also known as pellets, are one such dosage form. Pellets have been extensively investigated to develop controlled and delayed release oral formulations that release the active ingredients in the gastrointestinal tract at predetermined rates. The reason for their wide acceptance lies in their versatility that it can be used to target tissue in order to maximize the drug delivery at the desired site of action within the given period of time in the gastrointestinal tract ${ }^{1}$ As compared to single dosage form pellets are technically more complicated to manufacture, but it possess a number of advantages also. For instance, the pelletized product shows maximum drug absorption and reduced peak plasma fluctuation as they gets uniformly distributed in the gastrointestinal tract as subunits, thereby, Pellets are less susceptible to dose dumping and customized release profiles (pulsed, sustained or delayed) can be achieved by careful selection of polymers and method of preparation. Different chemically compatible as well as incompatible pellets can be combined together and delivered in the gastrointestinal tract either at the same sites or different sites. Even pellets of the same drug with different with release rates can be given in a single dosage form example capsule., ${ }^{2,3}$ Scientifically, pellets are substantially spherical mechanically strong agglomerates of powder particles, prepared by a specialized granulation process, known as pelletization, which was formed by the agglomeration of fine powdered excipient and drugs together that leads to the formation of small free flowing
Submission Date : 22-09-2014 Revision Date : 23-12-2014 Accepted Date : 28-01-2015

DOI: 10.5530/ijper.50.3.27 Correspondence: Mrs. Niti yadav, Assistant Professor, School of Pharmaceutical Sciences, IFTM University, Moradabad, INDIA.

E-mail: nitiyadav.pharma@ gmail.com

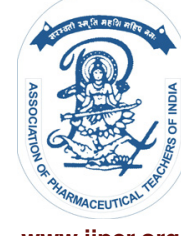

www.ijper.org 
spherical or semi spherical. ${ }^{4}$ Although both granulation and pelletization are agglomeration processes but they differ in the sense that in case of former, agglomerate produced are porous (20-50\%) and irregular (size range 0.1 to $2.0 \mathrm{~mm}$ ), whereas, pellets possess a uniform shape and size that ranges from $0.5-2.0 \mathrm{~mm}$, about $10 \%$ of low porosity and are free-flowing. ${ }^{5}$

Pharmaceutically pellets are versatile multiparticulate solid dosage form that can be amenable to both encapsulation into hard gelatin capsules or compression to form tablets and, therefore, may form an excellent carrier system for the controlled oral delivery of both low and high dose drugs. ${ }^{6,7}$

\section{Theories of Pellet Formation}

Pharmaceutical pelletization may also be defined as a process of forming nearly spherical macro particles by tumbling moist particulate fines, with addition of binders and other additives, in various pelletization equipments. Pellets were formed by subsequent reduction of effective air-water interface that leads to lowering of total surface free energy of the system, this driving force causes the conversion of fine powders into agglomerates and finally in the form of pellets. Two types of forces, physical and applied, are involved in this conversion. Physical forces give strength to the formed pellets via interfacial effects (capillary and surface tension forces), Van der Wall's interaction, interlocking effect among the particles and immovable liquid bridges. The change in the state of agglomerating system can in principle be accounted in terms of capillary and surface tension forces. The magnitude of capillary forces depends upon the types of bonds between the particles. These bonds, depending upon the relative proportion and distribution of the air and water phases in the pellet are referred to as pendular, funicular and capillary bonds. Due to tumbling motion of the pelletization equipment applied forces arise, this brings together individual wetted particle close to each other and hence physical forces become operative and pelletization process gets initiated. ${ }^{8}$ The mechanism of agglomerate formation and subsequent growth to a pellet believed to occur in the following stages-

1. Nucleation

2. Coalescence and Layering

3. Ball Growth Phase

Nuclei formation (Nucleation) refers to the formation of particles from the continuous phase due to interaction within the environment in itself. In nucleation, liquid bridges attached together three phase air-water-liquid nuclei to form primary particles (pendular in nature).
Smaller the particle sizes of nuclei better the bonding strength.' Transition phase occurs after Nucleation phase. This region is affected by the growth mechanism coalescence and layering. As soon as the initial formation of nuclei occurs, coalescence begins to set in. Coalescence causes discrete size changes and leads to decrease in number of agglomerates but not their mass. ${ }^{10,11}$ The third mechanism is layering which correspond to a slow growth phase; it involves the successive deposition of small fragments and fines on the previously formed nucleus. There is continuous change in the size of the particles due to their interaction with continuous phase. Layering can occur only when both the agglomerates and new feed are present. All these mechanisms take place simultaneously during any agglomeration process unless design and operating conditions are otherwise chosen. ${ }^{12}$ In ball growth phase the abrasion causes the transfer of material from one granule formed to another, this takes place in either of the direction, this mainly affects slow growth of agglomerated particles. ${ }^{13,14}$

\section{Size, shape and Strength of pellets for pharmaceutical use}

From pharmaceutical point of view, pellets as drug delivery carrier must have uniform size, almost spherical shape for better flow properties, prerequisite for subsequent encapsulation or compression, and sufficient mechanical strength to withstand abrasion during handling and further processing. To be used as oral controlled release product, pellets must disperse all along the gastrointestinal (GI) tract and exhibit prolonged GI transit time. For this to achieve, size and shape of pellets is very important. ${ }^{13}$ Hinder and Kelly in their work on gastric emptying of solids and liquids in canines reported that in the food-filled stomach plastic spheres of size range $7 \mathrm{~mm}$ remained there for long time even if the food itself expelled out of the stomach. ${ }^{14}$ The spheres began to transit in cluster form once the stomach had emptied completely. In another study on GI transit of pellets, Freely et al and Davies et al have investigated that smaller pellets $(2.4 \mathrm{~mm}$ in diameter) are not affected by the digestive functioning and the closing system of the stomach i.e pyloric sphincter. ${ }^{15}$ Bechgaard recommended that for the multiunit formulation the maximum pellet diameter should be of $1.5 \mathrm{~mm} \cdot{ }^{16-17}$ If the pellet size increases then it becomes uncertain to predict the emptying rate from the fed as it is highly variable.

The strength of pellets is a key factor in terms of handling, transportation, storage and further processing. It also affects physical properties such as dissolution and disintegration time. Strength of both wet and dry pellets should be considered. The strength of wet pellets 
is mainly due to the capillary forces. After drying of pellets, the capillary forces disappear and the forces contributing to the strength of dry pellets arise from hardening of bonding agents; precipitation of dissolved salts; friction and interlocking between the particles and electrostatic or Van der Wall's interactions. Binders are commonly used in order to improve the strength of the pellets. Influence of moisture content and granulating fluid on the pellet properties have been investigated by many researchers. ${ }^{18-36}$ Due to excess of moisture over wetting of the pellet occurs that leads to the agglomeration of large number of particles together while generation of fines occurs due to less amount of moisture. ${ }^{18}$ Various types of granulating fluid that can be utilized for the pellets formulation are: water, alcohol or water/alcohol mixtures. Milli and Schwartz ${ }^{37}$ have investigated while preparing formulation of Avicel $^{\circledR}$ PH101 and theophylline (90:10, w/w), that in order to produce good quality and quantity of pellets minimum of $5 \%$ of the granulation liquid had to be water. Hardness of the pellets increases if the water content of the granulation liquid increases. ${ }^{18}$

\section{Pelletization Techniques}

- Extrusion spheronization

- Layering Technique

- Cryopelletization

- Hot Melt Extrusion

- Freeze Pelletization

\section{EXTRUSION SPHERONIZATION}

Extrusion is a well known processing technology that has been developed over the last century. The unit operation of pelletization takes place in three steps-

- Feed preparation

- Pellet production

- Pellet curing

Feed preparation constitutes mixing of drug-excipient with desired additives such as solutions of binding agent(s). The second and most important step, agglomeration, is taken place in a pelletizer, where desired size pellets are formed. The final step is where wet pellets are cured either by thermal drying or by simple stockpiling. An extrusion spheronization process takes place in the following steps- Formation of plastic mass; Formation of extrudates; Breaking up of extrudates; Spheronization; Spherical pellets (Figure 1).

The pelletization operation begins with the dispensing of powder feed material together with binder solution to the granulator to form a plasticized wet mass. ${ }^{4}$ The plasticized mass so formed is then allowed to fall into the screening chamber of extruder. Here, extrusion or pressure blades provide sufficient compression to the plasticized wet mass against the exteriors of screen. The extruded material is firstly discharged into the discharge unit through the scrapper blade and then finally it is introduced into the spheronizer. Pelletizer disk makes to rotate extrudates at high speed to the vessel wall in the direction of rotation. This is similar to the formation of helix like structure as the rolling movement of the extrudates takes place in two dimensions. In short time duration the extrudate surface becomes smooth due to the intense rolling action. Finally smooth, round product called as Pellets is discharge at the discharge unit. ${ }^{38,39}$

The mechanism of formation of spherical pellets by extrusion spheronization can be understood via one of the two main models (Figure 2).

- According to first model, the cylindrical extrudates initial gets deformed into bent rope-shaped macro structures followed by transformation into a dumbbell shape structure which is twisted in the middle. Due to the twisting action the dumbbell structure breaks into two spheres, having hollow cavity at its flat side. This hollow sphere finally gets converted into the round smooth pellets by continuing the spheronization process.

- The second model describes a transformation in which the cylindrical extrudates were firstly gets converted into cylinder with rounded edges, followed by dumbbell-shaped structures, ellipsoids and finally, formation of spheres.

When preparing pellets with extrusion-spheronization process, in order to make sure that extrudates break into pieces of same length and diameter optimization of the process should be carried out. ${ }^{5}$ Extrudate should be in proper wet condition before entering the spheronizer in order to make sure that they can be spheronized properly and smoothly and no further breakdown should occur. Extrudate structure depends on the granulation step which takes place prior to spheronization. Formulation variables and the process parameters during granulation/extrusion process strongly influences the product quality of the pellets, than compared to parameters and variables during the spheronization process. ${ }^{40-43}$ Spheronization can be run continuously if the multiple pelletizer arranged in a cascade manner. Amount of the product in the pelletizer is strongly affected by the height of the discharge orifice. ${ }^{19}$

The type of extruders used causes the greatest variation in the process. During this process, as the name implies, it would be thought that it is essential to extrudate a formulation to produce spherical pellets. This however is not the case. Studies revealed that for a given for- 
mulation it was possible to produce good quality pellets from a particular formulation if the wet mass was subjected to simple oscillation granulator. Depending on the operation conditions different types of extruders produces different types of extrude. Extruders are not interchangeable and some formulations can be better suited to one than another, while in some cases it is only necessary to make a small adjustment in the liquid level to achieve successful interchange of extruders. There are various problems that were encountered during the process like binders were used during the spheronization in order to increase the strength of the pellets and it also reduces the amount of fine dust generated but too much binder makes the pellets hard, and it will also be difficult to obtain good spherical pellets. Similarly Lubricants used in the process increases the plasticity but also at the same time increase the amount of fine dust generation during spheronization. Water can also be used as a lubricant but if too much water is used, sticking can occur on the friction plate and bowl wall. Big lumps can also form if the large amount of pellets sticks together. In the same way high amount of fine dust will be generated if the extrudates are dry.

This process is more labor intensive than other pelletization technique and therefore should be considered when the other methods are not satisfactory or when it is important to produce sphere. Despite this, it is most widely used process of pelletization because spheres are the most common type of pellets. ${ }^{42}$

\section{LAYERING TECHNIQUE}

Another most commonly employed technique to produce spherical pellets is layering. This technique is further of two types: solution/suspension layering and powder layering Figure 3.44,45

In solution or suspension layering, powder feed material and other components are dissolved or suspended in the solvent. These solution or suspension is sprayed on the surface of the starter core and spread evenly as soon as it impinges on its surface. ${ }^{46}$ Spraying is followed by drying phase which allows dissolved material to get crystallized and thus between core and coating layer of the drug substance and among the consecutive layers of drug and polymers a solid bridges forms. ${ }^{47-48}$ It has been demonstrated that drying method affects the structural and functional properties of pellets. Like fluidized bed drying increases the dissolution rate of pellets due to increase pore diameter whereas lyophilized pellets show increase dissolution due to increase porosity of pellets.
In powder layering, the seeds (e.g. sugar spheres) are charged into the pelletizer and on its surface; the binder liquid and the powdered feed material (drug+excipient) is sprayed tangentially. The powder is properly distributed on to the surface of seed along with the rolling movement of it which confirms its spherical shape. It involves successive deposition of fine powder (drug and other components) and on the surface of starting core with the help of bridging liquid. Initially the drug particles get attached to the starter core with the help binding liquid that is sprayed on it; it forms a liquid bridge. Later on this liquid bridges gets replaced by the solid bridge which originates either from a binder in the solvent or from any material, that is soluble in the solvent medium. ${ }^{48}$ Conventionally coating pan was used for the manufacturing of pellets but it has several limitations like poor degree of mixing is very, inefficient drying. It is necessary to deliver the powder in such a manner and at a rate that should be in equilibrium with the binder liquid application rate throughout the process. Over wetting or dust generation may occur due to improper delivery rate of powder; this reduces the quality and yield of product. Other equipments used are Fluidized Bed Processor.

Fluidized Bed Processor (FBP): It is also called as Wurster Process. It performs multiple functions like coating, drying, granulation and pelletization. Controlled release formulations are particularly prepared by utilizing this technique. It involves successive deposition of several layers of the coating material. In the base plate of (FBP) spray nozzle is fitted with concurrent air flow through different perforation in the base plate resulting in a specific spray pattern. The particles which were to be coated are accelerated at high speed inside the wurster tube and coating solution is sprayed continuously through the spray case. ${ }^{49}$ As the process proceed further particles travelling upward get dried and fall outside the wurster tube back towards the base plate then back to the inside of the tube where they are once again accelerated by the spray. This process continued till the appropriate build up on the surface of particles takes place. The other types of fluidized bed processor include top spray, bottom spray, and tangential spray (Figure 4).

Critical parameter that has to be control is that powders may adhere to the sides of the hopper. If the bed temperature is high, powder is lost to the exhaust system. Therefore, binders are consistently used during solution/suspension layering to impart strength to the pellets. ${ }^{50}$ 


\subsection{CRYOPELLETIZATION}

Pellets were prepared by the utilization of Freeze drying method in this technique. Firstly this technique was utilized in the nutrition industry to develop lyophilized bacterial suspension in order to produce drug loaded pellets. Here in this technique liquid nitrogen at $-196^{\circ} \mathrm{C}$ is used as a fixing medium which causes freezing of droplet of liquid formulations into solid spherical particles which were then lyophilized to provide pellets. In this technique material gets freeze immediately and uniformly as a result of rapid heat transfer between the droplets and liquid nitrogen. In the conventional freeze drier the pellets were dried. The total quantity of nitrogen required in this technique depends upon the temperature of the solution being fixed. ${ }^{51}$

The equipment consist of a container below that a reservoir of liquid nitrogen is present in which a conveyor with transport baffle is immersed. Variable speed of the conveyor belts maintains the required residence time for freezing the pellets. The frozen pellets prior to drying were transported into storage container that is maintained at $-60^{\circ} \mathrm{C}$. In cryopelletization droplet formation is a critical step which is influenced by various factors such as formulation related variables (viscosity, surface tension and solid content), equipment design etc. ${ }^{52}$

\section{HOT MELT EXTRUSION (HME)}

HME is a robust and novel technique used in pharmaceutical industries for producing various drug delivery systems. It is a widely used process in plastic, rubber and food industries. This technique is applicable to the manufacture of variety of dosage forms like granules, pellets, tablets, implants etc. Melt extrusion process by utilizing polymers with high glass transition temperature (such as Polyvinyl Pyrrolidone) was firstly applied by BASF SE to pharmaceuticals. Later this technology was commercialized and several drugs were subsequently launched by Soliqs, the drug delivery business unit Abott $\mathrm{GmbH}$ and Co KG. ${ }^{53}$ This method involves compaction and conversion of blend of powder into uniform shape product. Polymers were melted and forced these polymers and active ingredients along with other additives through an orifice or die that were placed under controlled temperature, pressure, screw speed etc, to form products of different shapes and sizes (Figure 5). Whole process can be classified into following steps:

1. Feeding of the extruder through a hopper

2. Mixing, grinding and kneading

3. Flow through the die, and

4. Extrusion from the die and further downstream processing.

\section{Advantages of HME in development of formulations}

1. Drugs having poor bioavailability, its solid solution/ dispersion can be prepared by use of HME.

2. Taste masked dosage form of bitter drugs can be prepared by HME.

3. This technique is more desirable for drugs stability which is sensitive to water; as HME is solvent free and anhydrous method.

4. Drug particles were uniformly suspended with better content uniformity due to intensive mixing and agitation during the process.

Formulation development of controlled release system using HME involves selection of polymer, plasticizer, and releasing modulators that should be compatible with modulated drug. ${ }^{54}$

Drawbacks of the technology are often related to high energy input, and problems in handling and storage of low melting point binders, instability for heat labile material with high melting point binders as it requires high melting temperature. ${ }^{53}$

\section{FREEZE PELLETIZATION}

In this technique, a molten-solid carrier in which the drug is uniformly dispersed is allowed to enter as tiny droplets into an inert column of liquid in which the molten solid carrier is totally immiscible. This droplet gets solidifies into spherical pellets. These pellets can move in either direction i.e. move upward or downward depending upon the density of the molten solid carrier with respect to the liquid in the column. If the density of the molten-solid carrier is less than that of the liquid in the column then droplets are introduced from the bottom of the column, which then gets converted into solid pellets at the top portion of the column. Conversely, if the density of the molten-solid carrier is more than that of the liquid in the column then the droplets are introduced from the top of the column, and that gets solidify in the bottom portion of the column. ${ }^{55}$ Melting point of solid carrier used for this process should be below $100^{\circ} \mathrm{C}$ so that it remain in solid form at room temperature. It can be either hydrophilic or hydrophobic. In order to prevent the blockage of the needles and also to maintain the homogeneity in shape and size of the pellets The viscosity of the drug matrix should be low. The optimum viscosity of the liquid in the column should range between 4 and $40 \mathrm{cP}$ at $20^{\circ} \mathrm{C}$ to obtain spherical pellets. If the viscosity is much lower, molten solid droplets move rapidly in the column and lose their spherical shape. If the viscosity is greater, then the pellets move too slowly and they may form agglomerates. ${ }^{55}$ 


\section{MUPS (Multiple unit pellet system)}

MUPS mainly emphasis on the final dosage form, if the multiparticulate were formulated into single-unit dosage forms such as filling them into hard gelatin capsules or compressing them into tablets these are called as MUPS. In pharmaceutical industry and research perspective this term in general refers to MUPS compacted into tablet. They possess the advantages of both tablets and pellets filled capsules in one dosage form.

MUPS tablets should possess the following properties:

1. The compacted pellets should not fuse into a non disintegrating matrix during compaction. The MUPS tablets after swallowing must disintegrate rapidly into their subunits across the stomach and the small intestine.

2. Compaction process should not affect the drug release.

3. The polymeric coating present over the reservoirtype coated pellets within MUPS must be able to withstand the compression force; it may deform, but it should not rupture.

4. Pellet within the MUPS compacts must possess optimum physical strength to withstand the mechanical shocks encountered in their production, packaging, shipping and dispensing. Surface of compacted MUPS should be smooth and elegant and devoid of pinholes and other imperfections and should facilitate ease of film coating if needed.

MUPS manufacturing process constitutes of 2 steps: (1) Pellets manufacturing and (2) Tablet containing pellets manufacturing.

During the drug pellet manufacturing step, firstly blending of pellet components such as drug, cushioning excipients (these are those agents that take up the pressure of compaction by re-arranging themselves within the tablet structure or by preferentially getting deformed and/ or fractured. Thereby preventing damage to the coating on drug pellets. A binder liquid must be used (water or glycerol) for wet mixing. The mass obtained continues through the extrusion-spheronisation process and the drying of pellets recently formed can be performed in a fluid bed dryer. The next step, pellet coating, requires a careful selection of the excipients that will form the coating film in order to obtain the desired drug release. The tableting process will be performed by a rotary tablet press machine and tableting parameters like main compression force or speed constitute important issue. $^{56}$

\section{Coating of Pellets}

Coating is the process of applying coating material by spraying onto the moving bed of pellets with concurrent use heated air which facilitates evaporation of solvent.

The main objectives of coating of pellets are as follows:

1. In order to mask the taste, odour, and colour of the drug.

2. It avoids inactivation of drugs in stomach.

3. It prolongs the dosing interval.

4. It improves the patient's compliance.

5. It improves the appearance and texture of the dosage form.

Seal Coating: It is a coating applied directly to the pellets core for the purpose of separating pellets from the moisture in order to achieve good product stability. It also strengthens the pellet core. Since sealing coat develops a degree of tackiness at some times during drying process, so usually dusting powder is applied over the pellets to prevent them from sticking to each other and to the equipment surface.

Film Coating: It is a modern approach to surround pellets by a thin layer of polymeric material. It involves spraying a coating solution containing the following materials: polymer, solvent, plasticizer and colorants. The coating solution is sprayed on to the bed of moving of pellets followed by drying, which facilitates the removal of the solvent leaving behind the deposition of thin film of coating material around each pellet. Different types of coating are as follows:

1. Immediate release

2. Modified release

Enteric coating

Extended release

Enteric release coating: This type of coating provides barrier on the oral medication. It prevents the drug from the acidic $\mathrm{pH}$. (i.e. acidity) of the stomach.

Most enteric coatings work by presenting a surface that is stable at the highly acidic $\mathrm{pH}$ found in the stomach, but breaks down rapidly at a less acidic (relatively more basic) $\mathrm{pH}$.

Extended release: In this type of release system drug is dissolve over time in order to be released slower and steadier into the bloodstream while having the advantage of being taken at less frequent intervals than immediate-release (IR) formulations of the same drug. ${ }^{45}$ 


\section{EVALUATION OF PELLETS}

\section{SIZE DISTRIBUTION}

Pellets size is determined by sieve shaking method, microscopy, Scanning electron microscopy etc. The most widely used method for measuring particle size distribution is sieve shaking method. ${ }^{57-65}$ Direct method for determining particle size distribution is Microscopy. Diameter of pellets was measured via Optical microscopy and scanning electron microscope. Pellet size can also be determined by the use of vernier calliper. ${ }^{58}$

\section{PELLET SHAPE}

One of the prime requirements for successful coating is that the pellets should have spherical and smooth surface. There are several methods which is used to determine it like : microscopic and non-microscopic pictures of the object of an interest. Pellets shape is related to geometric shape and shape regularity (rugosity); it will affect the surface area, flow of particles, packing and compaction properties of the pellet..$^{54}$ It is possible to determine whether the shape of a particle is spherical or asymmetric. A sphere has minimum surface area per unit volume. Therefore, these properties can be compared for spheres and asymmetric pellets. The shape factor of a pellet can be expressed as the ratio of surface to volume. The minimum possible value for shape factor is 6 , which represents a sphere. If the ratio exceeds this factor 6 , the pellet is considered as asymmetric. ${ }^{66}$

\section{SURFACE MORPHOLOGY}

Scanning electron microscopy (SEM) is used to analyze surface morphology as well as cross section of pellets. ${ }^{67}$ Before examining the pellets in a SEM its coating were sputter with aluminum under argon atmosphere. ${ }^{54}$ For the examination of the microscopic structure of pellet surface use of optical microscopy was firstly reported by Sood et al., 2004 ${ }^{68}$ Micromeritic Properties of Pellets Angle of repose $(\theta)$ is the measure of frictional force between the pellets. It measures the angle between the horizontal plane and the surface of the pile of pellets. Angle of repose was calculated in order to know the flow property of matrix pellets. Tap density tester is used to determine the Tap density and bulk density of the pellets while granule density was determined by using petroleum ether displacement method. Roche Friability tester is used to assess the friability, a known mass of pellets were placed in the tester and then it is subjected to rotation at 25 RPM for 4 minutes in tester. ${ }^{69}$

\section{MECHANICAL STRENGTH}

Tensile strength: Tensile apparatus is used to determine the tensile strength. Pellets are strained with $5 \mathrm{~kg}$ load cell until failure occurs. Tensile strength is calculated by measuring the value of failure load and the radius of the pellets. ${ }^{70}$

Crushing strength: The crushing strength is the measure of load needed to break the pellets while elastic modulus is the measure load needed to begin plastic deformation. Material testing machine is used to measure the crushing strength and elastic modulus of 15 pellets (850-1000 $\mathrm{mm}$ size fraction). The upper mobile platen test speed was set at $1 \mathrm{~mm} / \mathrm{min} .^{70}$

\section{SPECIFIC SURFACE AREA}

Surface per unit volume is called as specific surface area. Size and shape of the pellets is directly affected by the specific surface area. If the film coating of the pellets is to be done then knowledge of the surface area is considerably important. It is important even in case of uncoated pellets, since surface area of the pellets directly influences the drug release profile. Specific surface area of pellets is determined by gas adsorption technique and air permeability method. ${ }^{54}$

Mathematical calculations: Surface area is calculated by $\pi r^{2}$, since smooth and dense spherical pellets has minimum surface area per unit volume, it can be characterized by its diameter. ${ }^{71}$

Air Permeability method: Surface area of pellet is the measure of hindrance that occurs to the flow of a fluid such as air through a plug of compact pellets. Greater the surface area per gram of pellet, greater the resistance to flow. ${ }^{71}$

Gas adsorption technique: In this technique, linear plot of the BET (Brunaer, Emmett and Teller) equation is used, to determine the volume of nitrogen adsorbed by the pellets contained in an evacuated glass bulb at different pressure. ${ }^{71}$

\section{DISINTEGRATION TIME}

Disintegration apparatus is used to measure disintegration time; it is an important characteristic for immediate release pellets. ${ }^{54}$ Disintegration of pellets can be perform in reciprocating cylinder method (USP Apparatus 3) or in a tablet disintegration tester consisting of transparent tubes attached with the sieve $(710 \mathrm{~mm})$ at the top and bottom of the tube. ${ }^{72-73}$ 


\begin{tabular}{|c|c|c|}
\hline & Table 1: MARKETED FORMULATION \\
\hline Brand Name & Drug & Company's Name \\
\hline Minocin Capsules & Minocycline Dihydrochloride & Triax Pharmaceutical's LLC \\
\hline Inderal LA Capsules Extended release & Propranolol & Slate Pharma. \\
\hline Testopel Pellets & Testosterone & Remedyrepack Inc. \\
\hline Omeprazole delayed release capsules & Omeprazole & Maylan Pharma. \\
\hline Astrix Capsules & Aspirin & Maylan Pharma. \\
\hline Doryx Capsules & Doxycycline & Maylan Pharma. \\
\hline Kadina Capsules & Morphine Sulphate & Titan Pharma.(India) Pvt. Ltd. \\
\hline Itraconazole Enteric coated Pellets & Itraconazole & Carnick Laboratories. Inc. \\
\hline Bontril SR & Phendimetrazine & Savage Laboratories,Banglore \\
\hline Brexin LA & Prochlorperazine & Smith and French ,Mumbai \\
\hline Compazine & Chlorpheniramine/Pseudoephedrine & Smith Kline and French, Mumbai \\
\hline Dilgard XL 180 & Diltiazem Hydrochloride & . \\
\hline
\end{tabular}

\section{IN VITRO DISSOLUTION STUDIES}

This is an important evaluation parameter which focuses on the release behavior of the dosage form. In order to establish the relationship between the in vitro release and in vivo absorption this test is carried out for different formulation in different dissolution media. Release behavior $r$ from the dosage form is influenced by its composition i.e. on type of polymer and binder used, characteristic of the pellets like: hardness, surface areas, and size of pellets, type of granulating liquid etc. and also by the drug properties like: aqueous solubility of the drug, physical properties of the drug in the pellet, and the presence of other additives like surfactants, polymers etc. ${ }^{73}$ In vitro dissolution studies are carried out either by using USP Apparatus I or USP Apparatus II. ${ }^{54}$

\section{Pharmaceutical Applications of Pellets}

\section{PELLET COMBINATIONS AS CONTROLLED RELEASE DRUG DELIVERY SYSTEMS -}

Different pellets with different release profile can be combined together and co-administered in order to get controlled release profile. Even different incompatible moieties can also be combined in the same dosage form. ${ }^{74}$

\section{PELLETS IN FAST DISSOLVING SYSTEMS}

For an immediate release of active moieties pellets are germane delivery systems. This technique allows the preparation of fast disintegrating and dissolving pellets, which provide a potential advantage of oral drug delivery systems. $^{74}$

\section{PELLETS AS SOLID SELF EMULSIFYING DRUG DELIVERY SYSTEMS (SSEDDS)}

SSEDDS are used inorder to improve the in vivo behavior of low solubility of drugs. By utilizing this technique intra and inter subject variability can be reduced and also the dose proportionality is also achieved. Self Emulsifying Drug Delivery Systems (SEDDS) is an emulsion in which firstly the drug particles were dispersed in oil phase along with suitable solubilizer then this dispersion is added to the aqueous phase in order to prepare an emulsion. Ad they are liquid dosage form the show several disadvantages such as less stable as compared to solid dosage form, storage and transport problem, etc. These disadvantages can be sort out by utilizing the SSEDDS. Various widely used techniques for their preparation are as follows: absorption by solid carriers, spray drying and melt methods. ${ }^{74-75}$

Although a number of formulations in the form of pellets are available in the market, few of them are listed in Table 1.

Table 2 shows a brief review of the research that was carried on pellets and pelletization technology in the last few years. ${ }^{75-88}$

Many inventors filed patents on pellets and pelletization technology as a versatile drug delivery system; however in this review only the patents filed in last five years are listed in Table $3 .^{89-97}$

\section{CONCLUSION}

This comprehensive review hereby concludes that pellet produced via extrusion spheronization, freeze pelleti- 


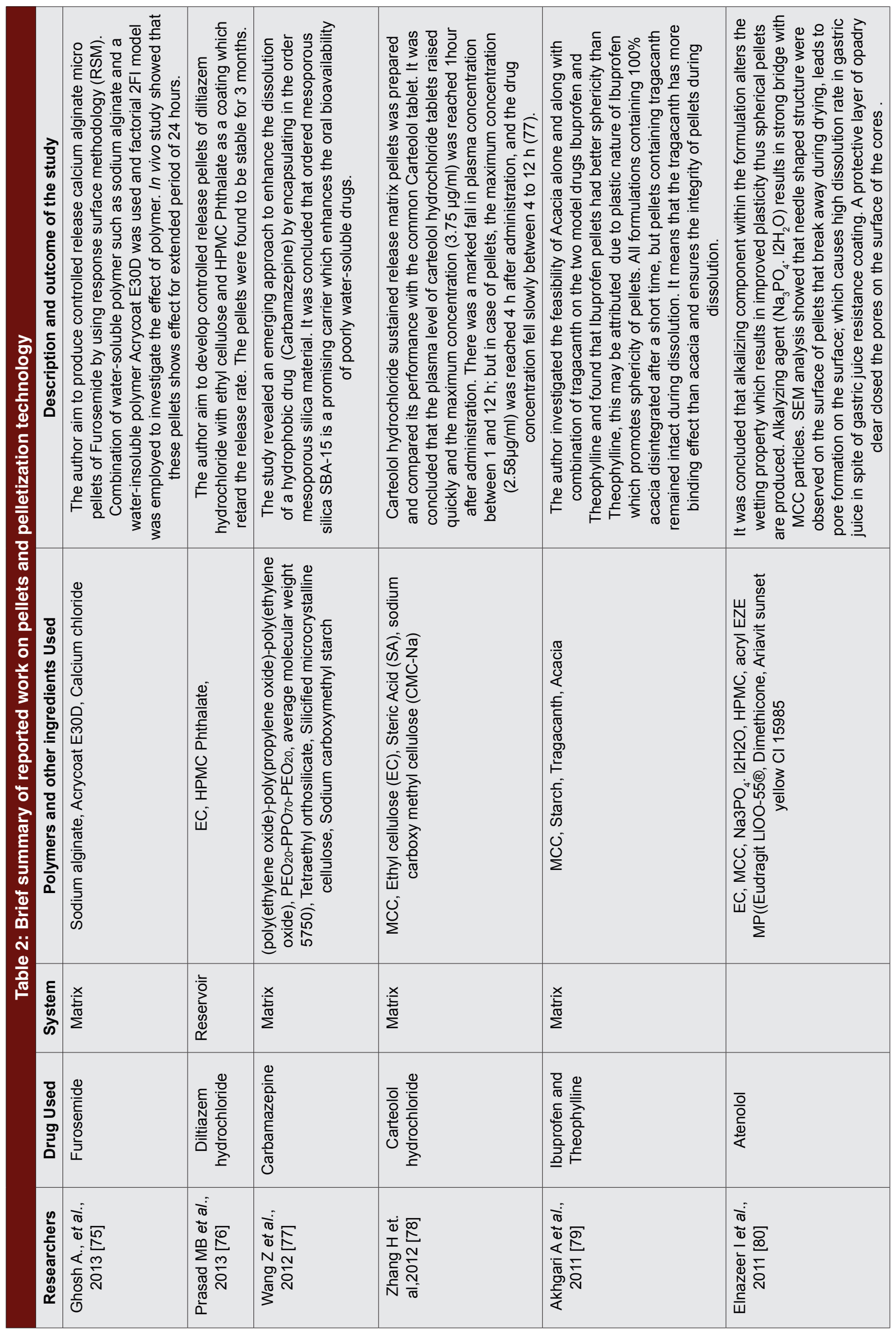




\begin{tabular}{|c|c|c|c|c|c|c|c|c|}
\hline 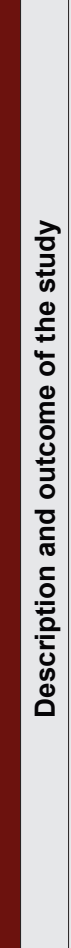 & 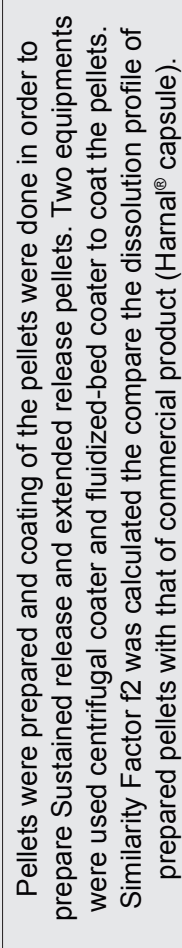 & 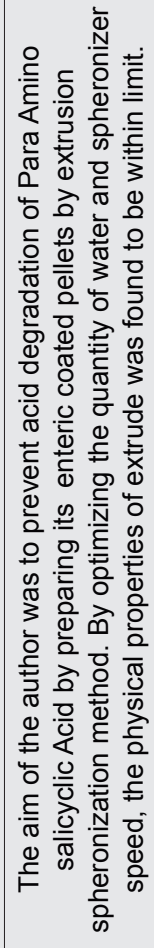 & 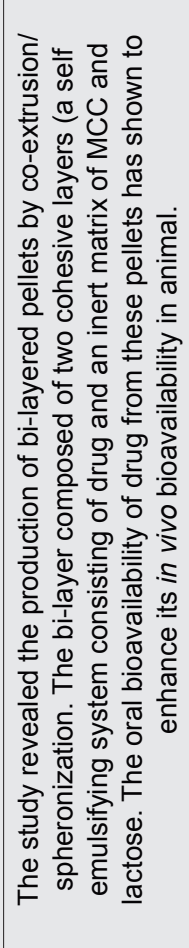 & 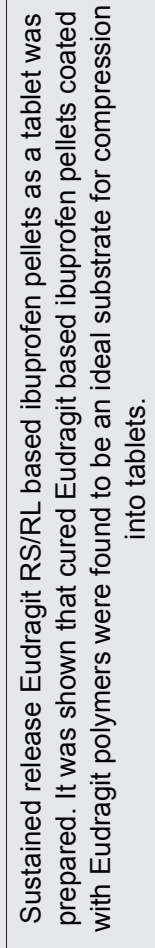 & 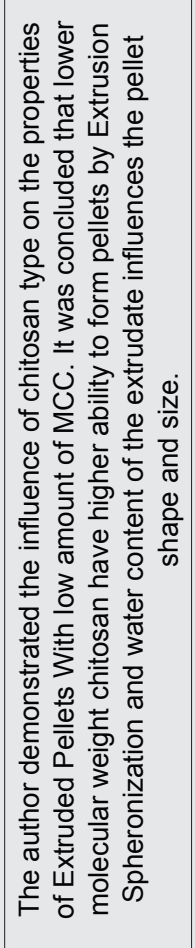 & 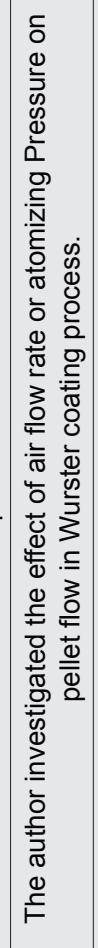 & 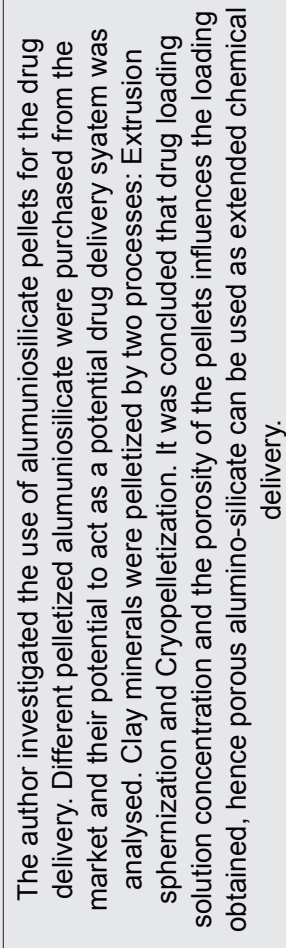 & 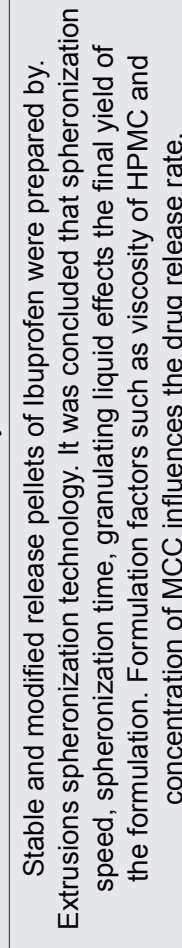 \\
\hline 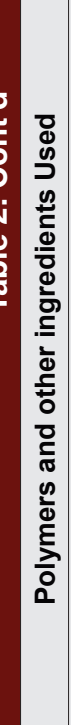 & 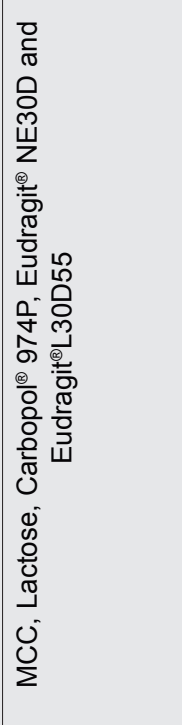 & 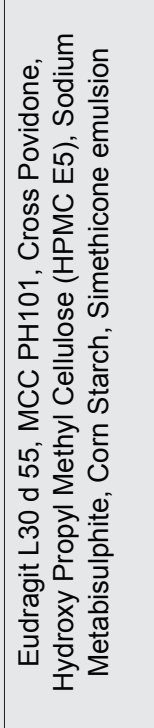 & 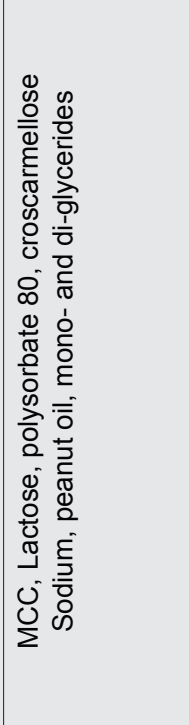 & 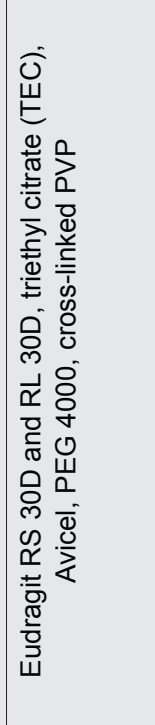 & 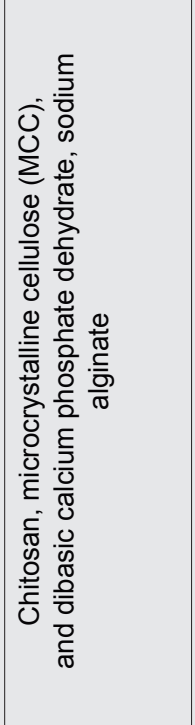 & 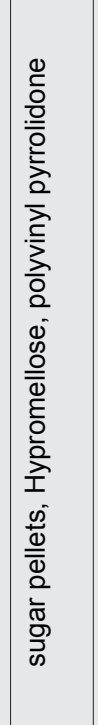 & 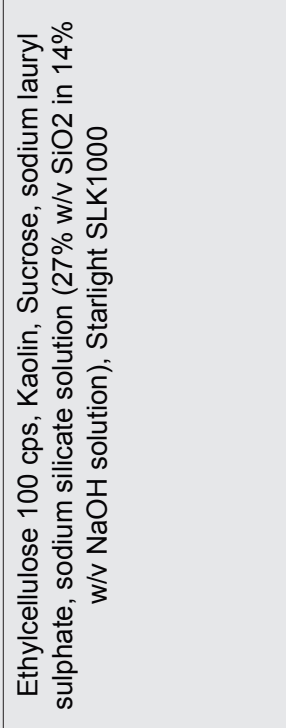 & 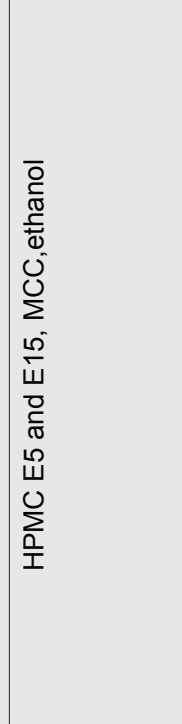 \\
\hline $\begin{array}{l}\frac{E}{\bar{v}} \\
\text { के } \\
\text { के }\end{array}$ & $\frac{\stackrel{x}{\underline{\underline{E}}}}{\sum^{\frac{x}{2}}}$ & 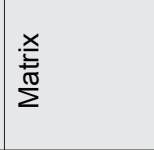 & $\begin{array}{l}\text { 萨 } \\
\text { 离 }\end{array}$ & 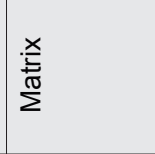 & $\begin{array}{l}\text { 䇏 } \\
\text { 离 }\end{array}$ & 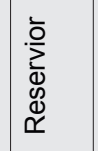 & $\begin{array}{l}\text { 竞 } \\
\text { 竞 }\end{array}$ & 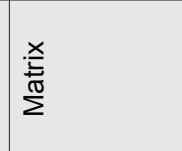 \\
\hline 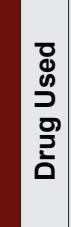 & 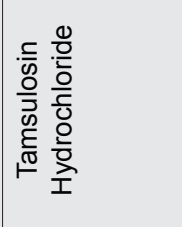 & 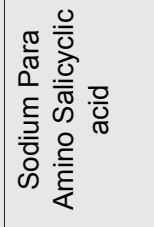 & 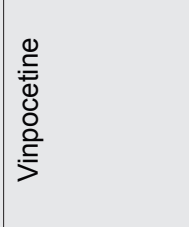 & 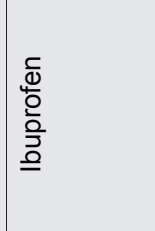 & 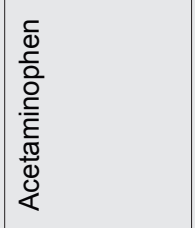 & & 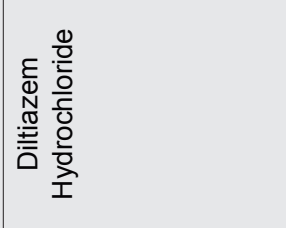 & 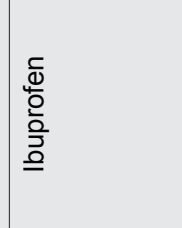 \\
\hline 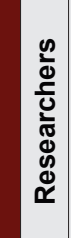 & 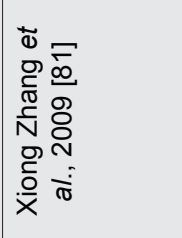 & 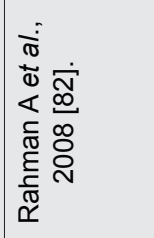 & 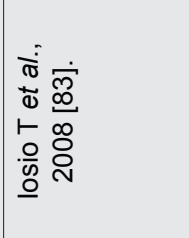 & 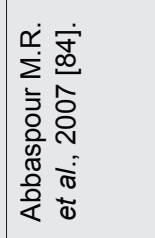 & 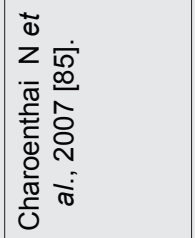 & 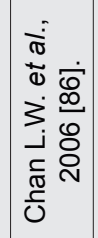 & 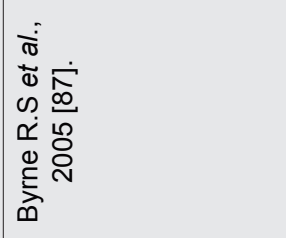 & 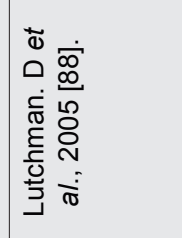 \\
\hline
\end{tabular}




\begin{tabular}{|c|c|c|c|}
\hline Patent Number & Patent & Inventor & Publication Date \\
\hline WO 2014124700 A1 & $\begin{array}{l}\text { Multiparticulate pharmaceutical } \\
\text { composition comprising a multitude of } \\
\text { two kinds of pellets }\end{array}$ & $\begin{array}{c}\text { Shraddha Sanjeev JOSHI, Ashish } \\
\text { Sharadchandra GUHA, Suresh Shahuraj } \\
\text { DOKE, Ashishkumar Prafulchandra } \\
\text { SHAH,Preeti Patil, }\end{array}$ & Aug 21, 2014 [89] \\
\hline WO 2013122554 A1 & $\begin{array}{l}\text { Pellet formulations comprising } \\
\text { esomeprazole }\end{array}$ & Mahmut Bilgic & Aug 22, 2013[90] \\
\hline W02012052178A3 & Improved Pharmaceutical Starter Pellets & $\begin{array}{l}\text { Istvan Antal, Jorg Bernard, Nikolett KIlai, } \\
\text { Imre Klebovich, Oliver Luhn }\end{array}$ & Jun. 21, 2012 [91] \\
\hline US $8318230 B 2$ & $\begin{array}{l}\text { Use of debranched starch in extrusion } \\
\text { spheronization pharmaceutical pellets. }\end{array}$ & $\begin{array}{c}\text { Aleksandra Dukic, Chris Vervaet,Jean } \\
\text { Paul Remon, Paul A. Altieri, Paul B.. } \\
\text { Foreman }\end{array}$ & Nov. 27, 2012 [92] \\
\hline WO 2011006611 A3 & Pellets formulation & $\begin{array}{c}\text { Svenja Gutsche, Heiko Kranz, Michael } \\
\text { Krause }\end{array}$ & Nov 24, 2011 [93] \\
\hline US 2010/0047340 A1 & $\begin{array}{l}\text { Hot-Melt extrusion of modified release } \\
\text { multi-particulates }\end{array}$ & $\begin{array}{c}\text { James W. McGinity; Austin, TX, Sandra } \\
\text { U. schilling }\end{array}$ & Feb. 25, 2010 [94] \\
\hline WO 2009090027 A8 & $\begin{array}{l}\text { Carrier pellets, method for the } \\
\text { production thereof and use thereof }\end{array}$ & $\begin{array}{c}\text { Antje Weigt, Wolfgang Kempe, Burkhard } \\
\text { Schlütermann }\end{array}$ & Oct 8, 2009 [95] \\
\hline US 2008/0220079 A1 & $\begin{array}{l}\text { Sustained Release compositions using } \\
\text { wax-like materials }\end{array}$ & Andrew Xian Chen;Patricia D. Kigin, & Sep. 11, 2008 [96] \\
\hline WO 2009002416A1 & $\begin{array}{l}\text { Controlled release Tamulosin } \\
\text { Hydrochloride Formulation }\end{array}$ & Xiu Xiu Cheng, Xiufang Cheng & Dec. 31, 2008 [97] \\
\hline
\end{tabular}

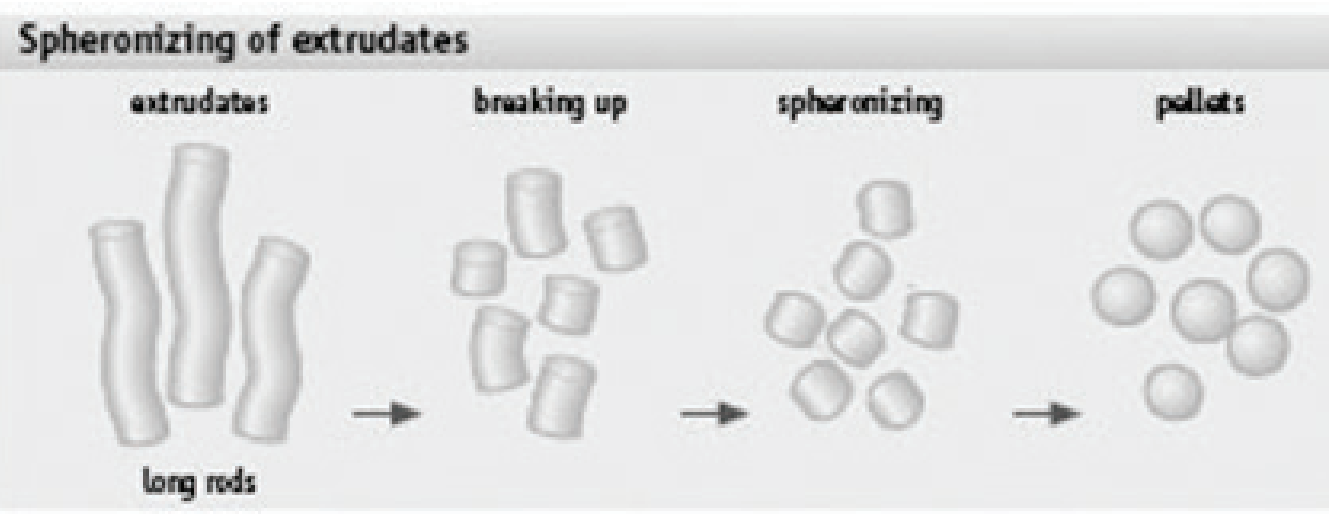

Figure: 1: Steps of pellet formation by extrusion spheronization process.

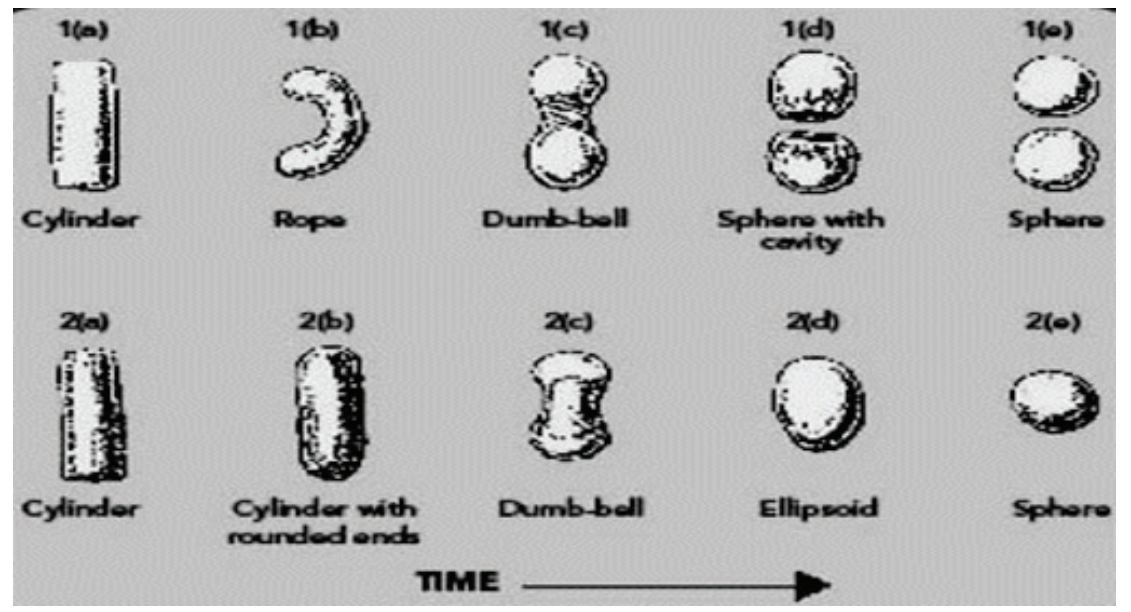

Figure: 2: Mechanism of pellet formation by extrusion spheronization process. 


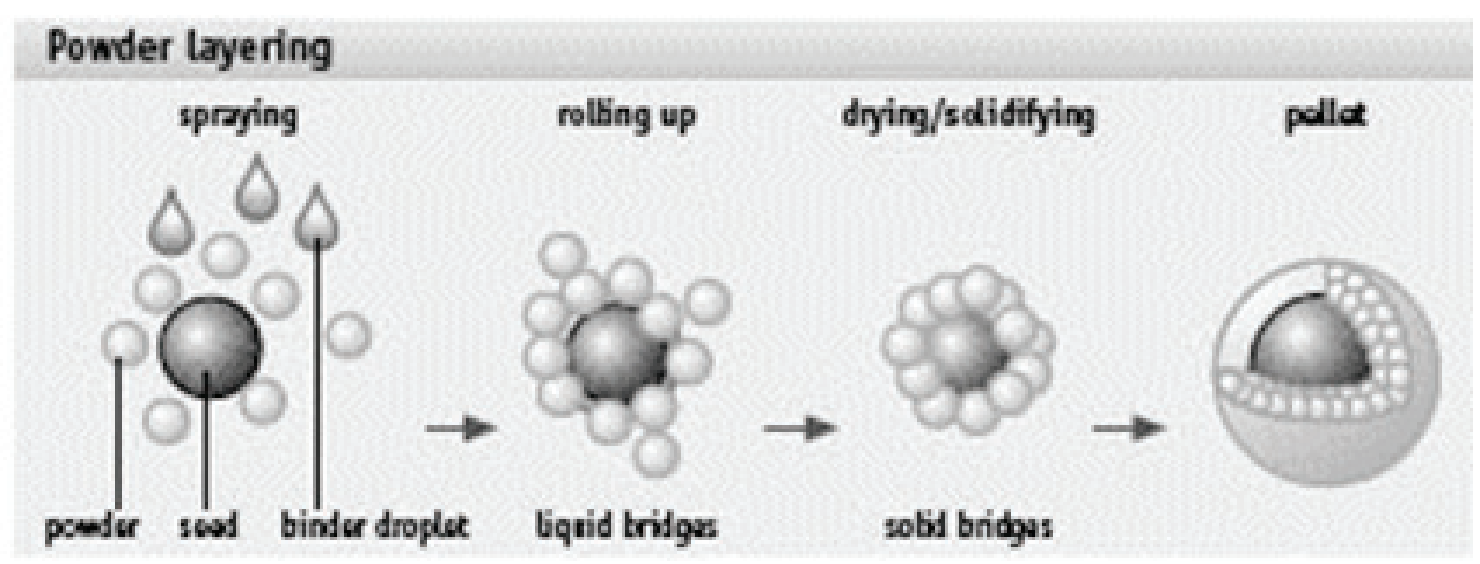

Figure: 3: Steps of pellet formation by powder layering process.

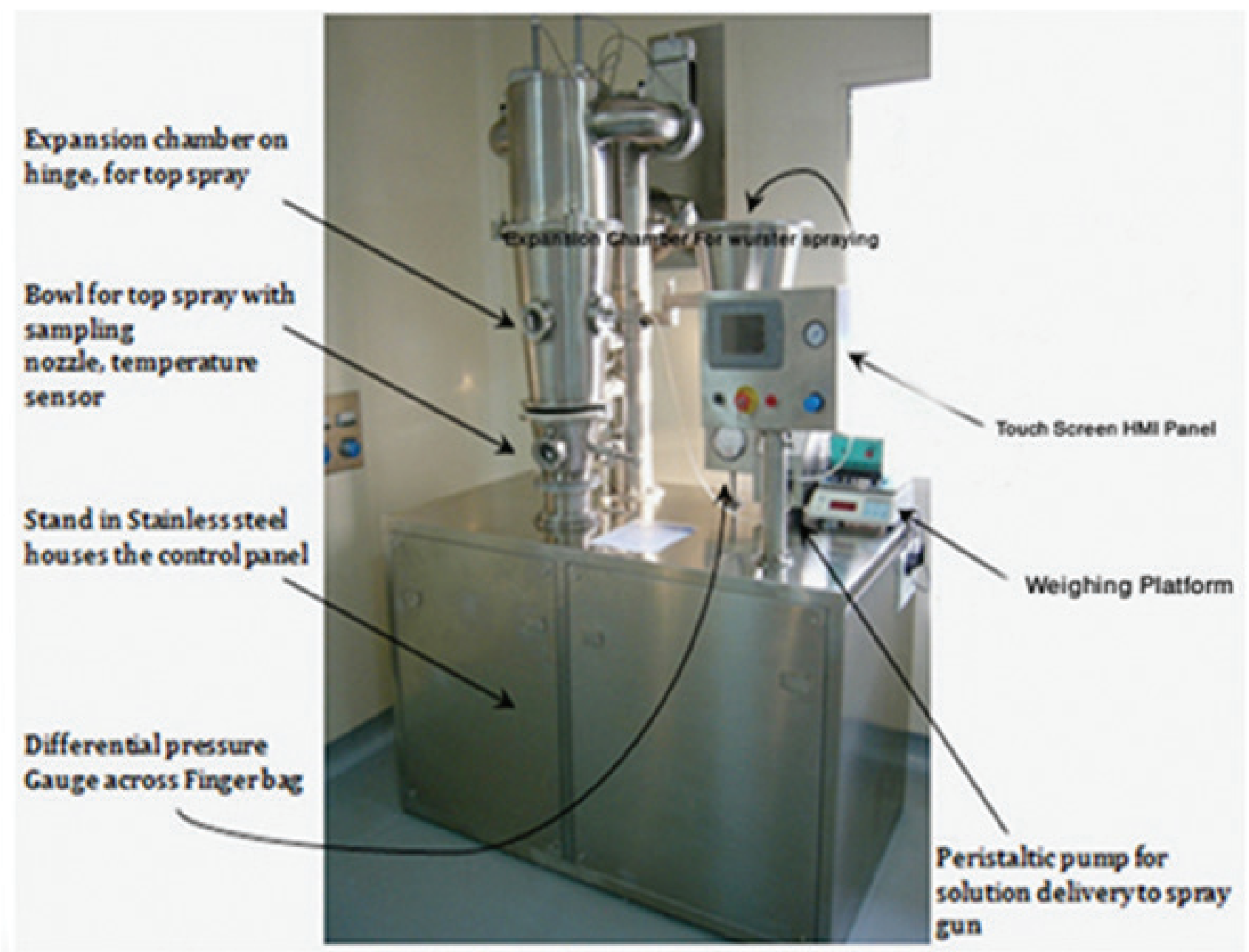

Figure: 4: Fluidized bed processor showing Top spray method. 


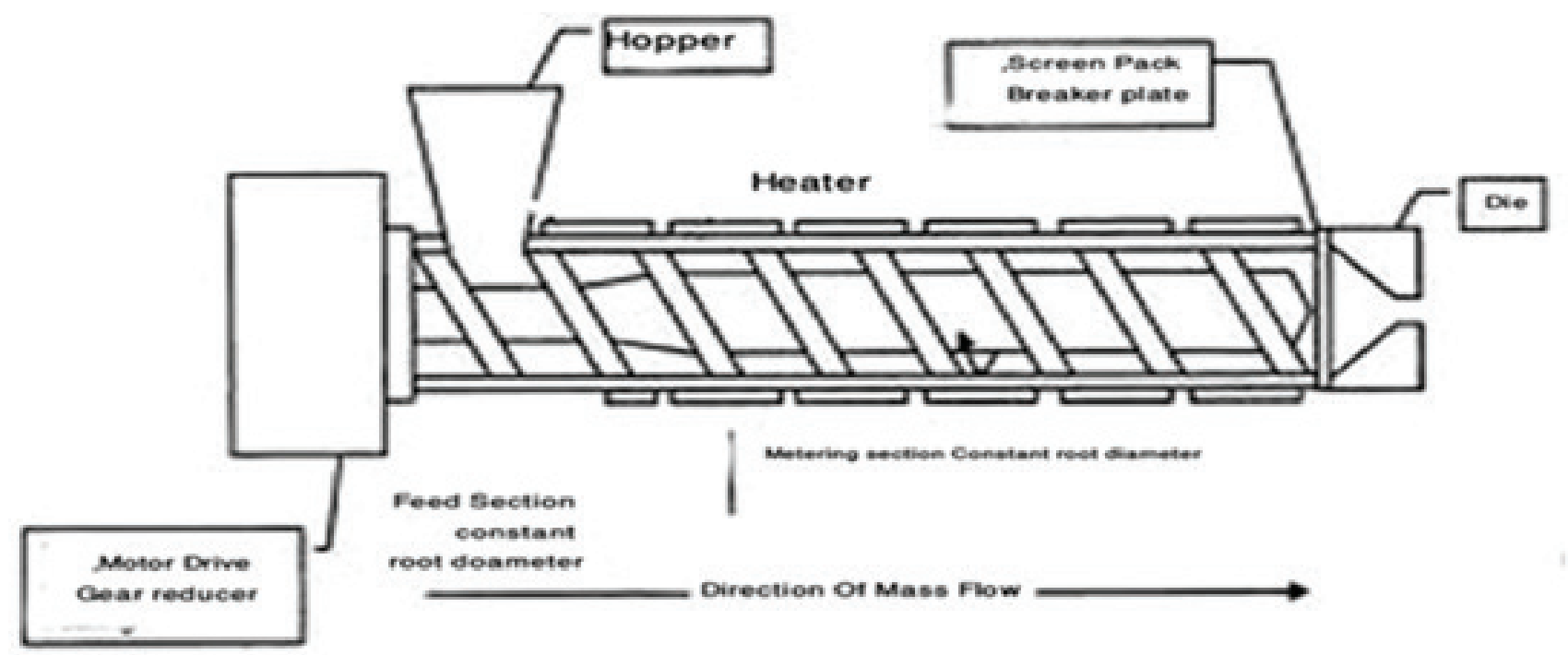

Figure: 5: Hot Melt extruder.

zation technology, cryopelletization and various other techniques are versatile carrier for oral controlled release dosage form .The major disadvantage of pellets produced by extrusion spheronization is that it is a time consuming process as it utilizes granulating liquid such as water and thus requiring drying phase while other novel pelletization techniques like cryopelletization involves freeze drying to remove water. But a major limitation is the use of nitrogen at $-196^{\circ} \mathrm{C}$. It can be conclude that due to good technological and biopharmaceutical advantages pelletization have gained importance in the modern pharmaceutical sciences and expected to play a major role as a carrier to control the release of drug. Most of the pharmaceutical companies develop pellets for wide range of active pharmaceutical ingredients.

\section{REFERENCES}

1. Trivedi N.R, Rajan M.G, Johnson J.R and Shukla A.J. Pharmaceutical approaches to preparing pelletized dosage forms using the extrusionspheronization process. Crit Rev Ther Drug Carrier Syst. 2007;24(1): 1-40. http://dx.doi.org/10.1615/CritRevTherDrugCarrierSyst.v24.i1.10; PMid:17430098.

2. Hirjau M, Nicoara A.C, Hirjau V and Lupuleasa D. Pelletization Techniques used in Pharmaceutical Fields. Pract Farm. 2011;4(3-4):206-211.

3. Ghebre- Sellassiel and Knoch A. Pelletization Techniques. In: Swarbrick J, editor. Encyclopedia of Pharmaceutical Technology, $3^{\text {rd }}$ Ed. Informa Healthcare. 2000;2651-2663:1242.

4. Dash V, Behera S.K, Agarwal R and Sinha N. Pelletization technique in drug delivery system. Jour Current Pharm Res. 2012;9(1):19-25.

5. Deb R and Baquee A.A. Pellet and Pelletization technique: A critical review. Int Res J Pharm. 2013;4(4):90-5.

6. Ghai D. Pelletization: An Alternate to Granulation. Pharma Times. 2011;43(11):13-5.

7. Bodmeier R. Tableting of coated pellets. Eur J Pharm Biopharm. 1997; 1(43): 1-8. http://dx.doi.org/10.1016/S0939-6411(96)00028-8.

8. Zheng $\mathrm{J}$. Formulation and analytical development for low-dose oral drug products.Pharmaceutical Sciences R\&D, Lilly Research Labs, Eli Lilly and Company. Wiley and sons. Inc., Publication.
9. Capes C.E. Particle size enlargement. In Williams JC, Allen T, editors. Handbook of Powder Technology, vol. 1, Elsevier, Amsterdam. 23-31:1980.

10. Justin L. Measurement of droplet size distribution and spray angle of pneumatic nozzle, and granule growth kinetics and properties of lactose, glucose and mannitol granules made in a fluidized bed granulator", Doctor's thesis, University of Helsinki: 1997.

11. Kristensen H.G and Schaefer. Granulation. A review of pharmaceutical wet granulation. Drug Dev Ind Pharm. 1987:13(4-5);803-872, http://dx.doi. org/10.3109/03639048709105217.

12. Mannivannan R and Parthiban K.G. Multiparticulate drug delivery systems: Pellet and Pelletization technique. Drug Invention Today. 2010;2(5) 233-7.

13. Palekar P, Shanbhag and Katdare K. Pelletization: A promising approach for tableting. Available from: http://www.pharmabiz.com/ArticleDetails. aspx?aid=77477\&sid=9.

14. Hinder R.A and Kelly K.A. Canine gastric emptying of solids and liquids. Am J Physiol. 1977;233(4):335-40.

15. Feely L.C, Khosla R and Davis S.S. Investigating the gastric emptying of different sizes of non-disintegrating tablets in humans using gamma scintigraphy. J Pharm Pharmacol. 1987;39:31.

16. Bechagaard $\mathrm{H}$ and Nielsen G.H. controlled release multiple unit and single unit doses. Drug Dev Ind Pharm. 1978;4(1):53-67. http://dx.doi. org/10.3109/03639047809055639.

17. Bechagaard $\mathrm{H}$. Critical factors influencing gastrointestinal absorption-what is the role of pellets?. Acta Pharm Technol. 1982;28(2):149-57.

18. Vervaet $C$, Baert $L$ and Remon J.P. Extrusion Spheronization: A literature review. Int J Pharm. 1995;116(2):131-46. http://dx.doi.org/10.1016/03785173(94)00311-R .

19. Nagamy V.D and Ayush S. Pelletization by Extrusion Spheronization : A detailed Review. All Res J Biol. 2012;3(2):10-23.

20. Dash V, Behera S.K, Agarwal R and Sinha N. Pelletization technique in drg delivery system. Jour Current Pharm Res. 2012;9(1):19-25.

21. Harrison P.J, Newton J.M and Rowe R.C. Convergent flow analysis in the extrusion of wet powder masses. J Pharm Pharmacol. 1984;36(12):796-8. http://dx.doi.org/10.1111/j.2042-7158.1984.tb04879.x; PMid:6151969.

22. Harrison P.J, Newton J.M and Rowe R.C. Flow defects in wet powder mass extrusion. J Pharm Pharmacol. 1985;37(2);81-3. http://dx.doi. org/10.1111/j.2042-7158.1985.tb05011.x ; PMid:2858554.

23. Gamlen M.J. Pellet manufacture for controlled release. Manuf Chem. 1985:55-9.

24. Heng P.W.S and Staniforth J.N. The effect of moisture on the cohesive properties of microcrystalline celluloses. J Pharm Pharmacol. 1988;40(5):360362. http://dx.doi.org/10.1111/j.2042-7158.1988.tb05267.x; PMid:2899633. 
25. Baert L, Fanara D, De. Baets P and Remon J.P. Instrumentation of a gravity feed extruder and the influence of the composition of binary and ternary mixtures on the extrusion forces. J Pharm Pharmacol. 1991;43(11):745-9. http://dx.doi.org/10.1111/j.2042-7158.1991.tb03475.x; PMid:1686900.

26. Bianchini R, Bruni G, Gazzaniga A and Vecchio C. Influence of extrusionspheronization processing on the physical properties of d-indobufen pellets containing pH adjusters. Drug Dev Ind Pharm. 1992;18(14):1485-503. http:// dx.doi.org/10.3109/03639049209040854.

27. Hasznos L, Langer I and Gyarmathy M. Some factors influencing pellet characteristics made by an extrusion spheronization process Part I.: Effects on size characteristics and moisture content decrease of pellets. Drug Dev Ind Pharm. 1992;18(4):409-37. http://dx.doi.org/10.3109/03639049209043861.

28. Newton J.M, Chow A.K and Jeewa K.B. The effect of excipient source on spherical granules made by extrusion-spheronization. Int Biophys. 1992;4:52-58.

29. Baert L, Vermeersch H, Remon J.P, Smeyers-Verbeke $J$ and Massart D.L. Study of parameters important in the spheronization process. Int J Pharm. 1993a;96(1-3):225-59. http://dx.doi.org/10.1016/0378-5173(93)90231-4.

30. Fielden K.E, Newton J.M and Rowe R.C. The influence of moisture content on spheronization of extrudate processed by a ram extruder. Int $\mathrm{J}$ Pharm. 1993;97(1):79-92. http://dx.doi.org/10.1016/0378-5173(93)90128-3.

31. Kleinebudde $\mathrm{P}$ and Lindner $\mathrm{H}$. Experiments with an instrumented twin-screw extruder using a single-step granulation/extrusion process. Int $\mathrm{J}$ Pharm. 1993;94(1):49-58. http://dx.doi.org/10.1016/0378-5173(93)90008-4.

32. C.C Ku, Joshi Y.M, Bergum J.S and Jain N.B. Bead manufacture by extrusion-spheronization-A statistical design for process optimization. Drug Dev Ind Pharm. 1993;19(13):1505-19. http://dx.doi.org/10.3109/ 03639049309069323.

33. Pinto J.F, Buckton $G$ and Newton J.M. The influence of four selected processing and formulation factors on the production of spheres by extrusion and spheronization. Int J Pharm. 1993;83(1-3):187-96 http://dx.doi. org/10.1016/0378-5173(82)90022-9.

34. Wan L.S.C, Heng P.W.S and Liew C.V. Spheronization conditions on spheroid shape and size. Int J Pharm. 1993;96(1):59-65. http://dx.doi. org/10.1016/0378-5173(93)90212-X.

35. Goodhart F.W, Draper J.R and Ninger F.C. Design and use of a laboratory extruder for pharmaceutical granulations. J Pharm Sci. 1973;62(1):133-6. http://dx.doi.org/10.1002/jps.2600620127 ; PMid:4682914.

36. Lindberg N.O, Tufvesson $\mathrm{C}$ and Olbjer L. Extrusion of an effervescent granulation with a twin screw extruder, Baker Perkins MPF 50 D. Drug Dev Ind Pharm. 1987;13(9-11):1891-913. http://dx.doi. org/10.3109/03639048709068698.

37. Millili G.P and J.B Schwartz. The strength of microcrystalline cellulose pellets: the effect of granulating with water/ethanol mixtures. Drug Dev Ind Pharm. 1990;16(8):1411-26. http://dx.doi.org/10.3109/03639049009115970.

38. www. Extrusion pellet technology.

39. Schmidt $C$ and Kleinebudde P. Influence of granulation steps on pellets prepared by extrusion Spheronization. Chem Pharm Bull. 1990;47(3):405-12. http://dx.doi.org/10.1248/cpb.47.405.

40. Erkoboni D.F.Extrusion-spheronisation as a granulation technique", In: Parikh DM, editor. Handbook of pharmaceutical granulation technology. New York: Marcel Dekker. 1997.334-65.

41. DukiC-ott A, Thommes $M$, Remon J.P, Kleinebudde $P$ and Vervaet $C$. Production of pellets via extrusion spheronisation without the incorporation of microcrystalline cellulose: A critical review. Eur J Pharma Biopharm. 2009; 71(1):38-46. http://dx.doi.org/10.1016/j.ejpb.2008.08.005; PMid:18771727.

42. Ku CC, Joshi YM, Bergum JS and Jain NB. Bead manufacture by extrusionspheronisation - A statistical design for process optimization. Drug Dev Ind Pharm. 1993;19(1):1505-19. http://dx.doi.org/10.3109/03639049309069323

43. Harold F, Giles Jr, Eldrich M, Mount I, John R, et al. Extrusion: The definitive processing guide and handbook, $1^{\text {st }}$ ed. PDL handbook Series. 2007:13-4.

44. Jittima C, Suzanne B.J, Michael N and Fridrun P, "The Preparation of Spherical Granules by Extrusion/Spheronization without Microcrystalline Cellulose", Pharmaceutical technology europe ,2004, Available from: http:// www.pharmtech.com/pharmtech/Analytical/The-Preparation-of-SphericalGranules-by-Extrusion/ArticleStandard/Article/detail/130254
45. Woodruff C.W and Nuessle N.O. Effect of processing variables on particles obtained by extrusion-spheronization processing. J Pharm Sci. 1972;61(5): 787-90. http://dx.doi.org/10.1002/jps.2600610525; PMid:5035792.

46. Chapman S.R, Rowe R.C and Newton J.M. Characterization of the sphericity of particles by the one plane critical stability. J Pharm Pharmacol. 1988;40(7):503-05. http://dx.doi.org/10.1111/j.2042-7158.1988.tb05286.x; PMid:2904992.

47. Eskilson C. Controlled release by encapsulation. Manuf chem. 1985;56:33-41.

48. Reynolds $A D$. A new technique for production of spherical particles. Manufacturing Chemist. 1970;41(6):40.

49. http://www.glatt.com/cm/fileadmin/material/glatt-times_no33.pdf .

50. http://www.spray.com/pharmcatalog/pdf/c12_fluid_bed_processing.pdf.

51. Kumar V, Mishra S. K, Lather A and Ranjit V.S. Multiple unit dosage formpellet and pelletization technique: An overview. Int Jour of Ayurveda and Pharmacy. 2011;2(1):121-5.

52. Supria P, Ranji B and Rana A.C. Pelletization Technique a literature review. Int res j pharm, 2012;3(3):43-47.

53. Jana S and Miloslava R. Hot melt extrusion. Ceska Slov Farm. 2012;61(3): 87-92. PMid:22913823.

54. Rahman MA, Ahuja A, Baboota S, Bali V, Saigal N, et al. Recent advances in pelletization technique for oral drug delivery: a review. Current drug delivery. 2009 Jan 1;6(1):122-9. http://dx.doi.org/10.2174/156720109787048339; PMid:19418964.

55. Cheboyina $S$ and Wyandt CM. Wax-based sustained release matrix pellets prepared by a novel freeze pelletization technique: I. Formulation and process variables affecting pellet characteristics. International journal of pharmaceutics. 2008 Jul 9;359(1):158-66. http://dx.doi.org/10.1016/j. ijpharm.2008.04.011; PMid:18499369.

56. Reddy S, Das P, Das H and Ghosh A. MUPS (Multiple Unit Pellet System) Tablets :A Brief Review. Journal of pharmaceutical and biomedical sciences. 2011;12 (02):1-5.

57. Niskanen M, Yliruusi J.K and Niskanen T. The effects of particle size of caffeine on pellets properties. Acta Pharm. Fenn. 1990c;99:129-40.

58. Wiwattanapatapee R, Pengnoo A, Kanjanamaneesathian M, Matchavanich $L$ and Janatharangsi $A$. Floating pellets containing bacterial antagonist for control sheath blight of rice. Formulations, viability and bacterial release studies. J. Control. Release. 2004;95(3):455-61. http://dx.doi.org/10.1016/j. jconrel.2003.12.024; PMid:15023457.

59. Niskanen M. Powder layering and coating in a centrifugal granulator: Effect of binder- solution concentration, powder particle size and coating amount on pellets properties. Doctor's Thesis, University of Helsinki. 1992.

60. Hellén L, Yliruusi J, Muttonen E and Kristoffersson E. Process variables of the radial screen extruder. Part II: Size and size distribution of pellets. Pharm Techn. Int. Biophys., 1993a;5(2):44-53.

61. Hellén L, Yliruusi J, Muttonen E and Kristoffersson E. Process variables of the radial screen extruder. Part III: Shape, surface and flow properties of pellets. Pharm Techn Int Biophys. 1993b:5(3):38-48.

62. Hellén L. Evaluation of the essential process variables of the Nica pelletising equipment. Doctor's thesis, University of Helsinki. 1992.

63. Schaefer T.Equipment for wet granulation. Acta Pharm Suec. 1988;25(4-5): 205-28.

64. Schaefer T, Holm P and Kristensen H.G. Melt granulation in a laboratory scale high shear mixer. Drug Dev Ind Pharm. 1990;16(8):1249-77. http:// dx.doi.org/10.3109/03639049009115960.

65. Schæfer $T$ and Mathiesen C. Melt pelletization in a high shear mixer. IX. Effects of binder particle size. International Journal of Pharmaceutics. 1996 Aug 9;139(1):139-48. http://dx.doi.org/10.1016/0378-5173(96)04548-6.

66. Mezreb N, Charrueau C, Boy P, Allain P and Chaumeil J.C. Production of Carbopol 974P and Carbopol 971P pellets by extrusion spheronization. Optimization of the processing parameters and water content. Drug Dev Ind Pharm. 2004;30(5):481-90. http://dx.doi.org/10.1081/DDC-120037476; PMid:15244083.

67. Eerikainen $S$ and Lindqvist A.S. The behaviour of various fillers inspheronized uncoated and film-coated granules containing slightly watersoluble indomethacin. Int J Pharm. 1991;75(2-3):181-92. http://dx.doi. org/10.1016/0378-5173(91)90192-Q. 
68. Sood A, Ashokraj $\mathrm{Y}$ and Panchagnula R. A multiunit matrix-based particulate system for controlled delivery of nifedipine. Pharmaceutical Technology. 2004;28(11):84-102.

69. Steckel $\mathrm{H}$ and Mindermann-Nogly F. Production of chitosan pellets by extrusion spheronization. Eur J Pharm Biopharm. 2004;57(1):107-14. http:// dx.doi.org/10.1016/S0939-6411(03)00156-5.

70. Chatlapalli R and Rohera Bhagwan D. Physical characterization of HPMC and HEC and investigation of their use as pelletization aids. Int $\mathrm{J}$ Pharm. 1998;161(2):179-93. http://dx.doi.org/10.1016/S0378-5173(97)00350-5 .

71. Martin A. Physical pharmacy: Physical Chemical Principles in the Pharmaceutical Sciences. $4^{\text {th }}$ edition, Lippincott Williams \& Wilkins, 1993.

72. Thommes $\mathrm{M}$ and Kleinebudde $\mathrm{P}$. Use of $\mathrm{k}$-carrageenan as alternative pelletization aid to microcrystalline cellulose in extrusion/spheronisation, I. Influence of type and fraction of filler. Eur J Pharm Biopharm. 2006;63(1):5967. http://dx.doi.org/10.1016/j.ejpb.2005.10.003 http://dx.doi.org/10.1016/j. ejpb.2005.10.002 ; PMid:16326085.

73. Huyghebaert N, Snoeck V, Vermeire A, Cox E, M.B Goddeeris, et al. Development of an enteric-coated pellet formulation of F4 fimbriae for oral vaccination of suckling piglets against enterotoxigenic Escherichia coli infections. Eur J Pharm Biopharm. 2005;59(2):273-81. http://dx.doi. org/10.1016/j.ejpb.2004.08.007; PMid:15661499.

74. Politis N.S and Rekkas D.M. Pelletization processes for pharmaceutical applications:APatentReview. RecentPatentsonDrugDeliveryandFormulation. 2011;5(1):61-78. http://dx.doi.org/10.2174/187221111794109493.

75. Ghosh A, Chakraborty P. Formulation and Mathematical Optimization of Controlled Release Calcium Alginate Micro Pellets of Frusemide. BioMed Research International. 2013; Article ID 819674, 14 pages.

76. Yuvraj T.V, Kumar G. A, Naidu Y. V and Sudheer B. Pellets in pharmaceutical technology. Int Jour Pharma Res Devt. 2010;2(2):36-42.

77. Wang Z, Chen B, Feng Li G.Q, Wu Q, Dian L et al., Increasing the oral bioavailability of poorly water-soluble carbamazepine using immediate release pellets supported on SBA-15 mesoporous silica. International Journal of Nanomedicine. 2012;7:5807-18. PMid:23209366 PMCid:PMC3509994.

78. Zhang H, Luo Y.H, Zhao X.Y, Chen Q, Luo M, Luo L.Y et al. Preparation of carteolol hydrochloride matrix sustained-release pellets and evaluation in vitro/in vivo. African Journal of Pharmacy and Pharmacology. 2012;6(11):829-33. http://dx.doi.org/10.5897/AJPP11.751.

79. Akhgari A, Abbaspour MR and Pirmoradi S. Preparation and evaluation of pellets using acacia and tragacanth by extrusion-spheronization. Daru. 2011;15;19(6):417-23

80. Elnazeer I, Bajdiln H, Sovány T and Pintye-Hódi K. Delayed release matrix pellet preparation containing an alkalizing pore-former agent. Chemical Engineering Research and Design. 2011;89(7):1006-110. http://dx.doi. org/10.1016/j.cherd.2010.12.003.

81. Zhang $X$, Tang $X$ and Yang R. Development of a Tamsulosin Hydrochloride Controlled-Release Capsule Consisting of Two different coated pellet. Drug
Development and Industrial Pharmacy. 2009;35(1):26-33. http://dx.doi. org/10.1080/03639040802144203 ; PMid:18686088.

82. Rahman A, Ali. Development and in vivo evaluation of enteric coated system for multiparticulate system for resistant tuberculosis. Ind J Pharm Sci. 2008.

83. Iosio T, Voinovich D, Grassi M, Pinto J, Perissutti B, Zacchigna M et al. Bi-layered self-emulsifying pellets prepared by co-extrusion and spheronization: Influence of formulation variables and preliminary study on the in vivo absorption. European Journal of Pharmaceutics and Biopharmaceutics. 2008;69(2):686-97 http://dx.doi.org/10.1016/j.ejpb.2007.11.014; PMid:18191390.

84. Abbaspour M.R, Sadeg F and Garekani H. Design and study of ibuprofen disintegrating sustained-release tablets comprising coated pellets. European Journal of Pharmaceutics and Biopharmaceutics. 2008;68(3):747-59. http:// dx.doi.org/10.1016/j.ejpb.2007.09.010 ; PMid:17977701.

85. Nattawut $\mathrm{C}$, Kleinebudde $\mathrm{P}$ and Puttipipatkhachorn $\mathrm{S}$. Influence of Chitosan Type on the Properties of Extruded Pellets With Low Amount of Microcrystalline Cellulose. AAPS Pharm Sci Tech. 2007;8(3):64

86. Chan L.W, Elaine Tang S.K and Heng P.W.S. Comparative Study of the Fluid Dynamics of Bottom Spray Fluid Bed Coaters. AAPS Pharm Sci Tech. 2006;7(2):37. http://dx.doi.org/10.1208/pt070237.

87. Byrne $R$ and Deaasy P.B. Use of porous aluminosilicate pellets for drug deliver. Journal of Microencapsulation. 2005;22(4):423-37. http://dx.doi. org/10.1080/02652040500100196 ; PMid:16214789.

88. Lutchman D and Dangor C.M , Perumal D. Formulation of rate-modulating pellets for the release of ibuprofen: An extrusion-spheronization process. Journal of Microencapsulation. 2005;22(6):643-59. http://dx.doi.org/10.1080/ 02652040500162535 ; PMid:16401580.

89. Joshi I, Guha A, Doke S, SHAH A, Patil P. Multiparticulate pharmaceutical composition comprising a multitude of two kinds of pellets. WO 2014124700 A1. Aug, 21, 2014.

90. Bilgic M. Pellet formulations comprising esomeprazole. WO 2013122554 A1. Aug 22, 2013.

91. Antal I, Bernard J, Kllai N, Klebovich I and Luhn O. Improved Pharmaceutical Starter Pellets. W02012052178A3, Jun;21:2012.

92. Dukic A, Vervaet C, Remon J. P, Altieri P.A and Foreman P.B. Use of debranched starch in extrusion spheronization pharmaceutical pellets. US 8,318,230, Nov. 27, 2012.

93. Gutsche S, Kranz H and Krause M. Pellets formulation. WO 2011006611 A3, Nov 24:2011.

94. McGinity J. W, Austin TX and Schilling S. U. Hot-Melt extrusion of modified release multi-particulates. US 2010/0047340 A1, Feb. 25: 2010.

95. Weigt $A$, Kempe $W$ and Schlutermann B. Carrier pellets, method for the production thereof and use thereof. WO 2009090027 A8, Oct 8: 2009.

96. Chen A.X and Kigin P.D. Sustained Release compositions using wax-like materials. US 2008/0220079 A1, Sep. 11: 2008.

97. Cheng X.X and Cheng X. Controlled release Tamulosin Hydrochloride Formulation. WO 2009002416A1, Dec. 31: 2008. 